\title{
Integrated strategies to tackle the inequitable distribution of doctors in Thailand: four decades of experience Suwit Wibulpolprasert*1 and Paichit Pengpaibon*2
}

\author{
Address: ${ }^{1}$ Deputy Permanent Secretary, Ministry of Public Health, Thailand and ${ }^{2}$ Office of Permanent Secretary, Ministy of Public Health, Thailand \\ Email: Suwit Wibulpolprasert* - suwit@health.moph.go.th; Paichit Pengpaibon* - ppaichit@pengpaiboon.th \\ * Corresponding authors
}

This article is available from: http://www.human-resources-health.com/content/l/1/12

(C) 2003 Wibulpolprasert and Pengpaibon; licensee BioMed Central Ltd. This is an Open Access article: verbatim copying and redistribution of this article are permitted in all media for any purpose, provided this notice is preserved along with the article's original URL.

\begin{abstract}
Inequitable distribution of doctors with high concentration in urban cities negatively affects the public health objective of Health for All. Thus it is one of the main concerns for most health policy makers, particularly in developing countries. This paper aims to summarize strategies to solve inequitable distribution of human resources for health $(\mathrm{HRH})$ between urban and rural areas, by using four decades of experience in Thailand as a case study for analysis.
\end{abstract}

\section{Introduction}

Maldistribution of human resources for health is a worldwide phenomenon and may appear in different dimensions [1]. The first and greatest concern is inequitable distribution, particularly of professionals such as doctors. The concentration of doctors is usually highest in developed countries and cities, with better living standards, higher income, more social recognition and greater job satisfaction. The second form of maldistribution is in skill mix. Many countries, such as Bangladesh, Brazil, China and Pakistan, have more doctors than nurses. The third is the problem of overspecialization. The fourth is institutional maldistribution. Last, there is gender maldistribution.

Multiple factors influence the inequitable distribution of doctors, ranging from general social and economic inequity, the medical education system, payment incentives, public/private health system development and a social movement for reform (Fig. 1) [2]. A movement towards increasing private sector involvement in health services, fee-for-services payment under a user fee system, poorly managed decentralization, and increasing income maldis- tribution usually result in a shift of HRH in favor of the big cities, private hospitals and specialized services.

In contrast, investment in public health, cost containment, case or capitation payment systems, improved income distribution and effective decentralization usually favour the distribution of HRH towards the rural population, the urban poor, and to public primary care services, with a resultant increased need for more lower level cadres of HRH [1]. Thus the problem of inequitable distribution of doctors should be considered part of overall social inequity, as well as a problem in health system management.

\section{Overview of the rural public health system in Thailand}

Thailand is a lower middle-income developing country with a population of 62.3 million in $2002,65 \%$ of which resides in rural areas. The country is divided into 75 provinces, 774 districts, 81 subdistricts and 6397 communes called Tambons [3].

One main activity of early health system development in Thailand was to establish schools to produce a health 


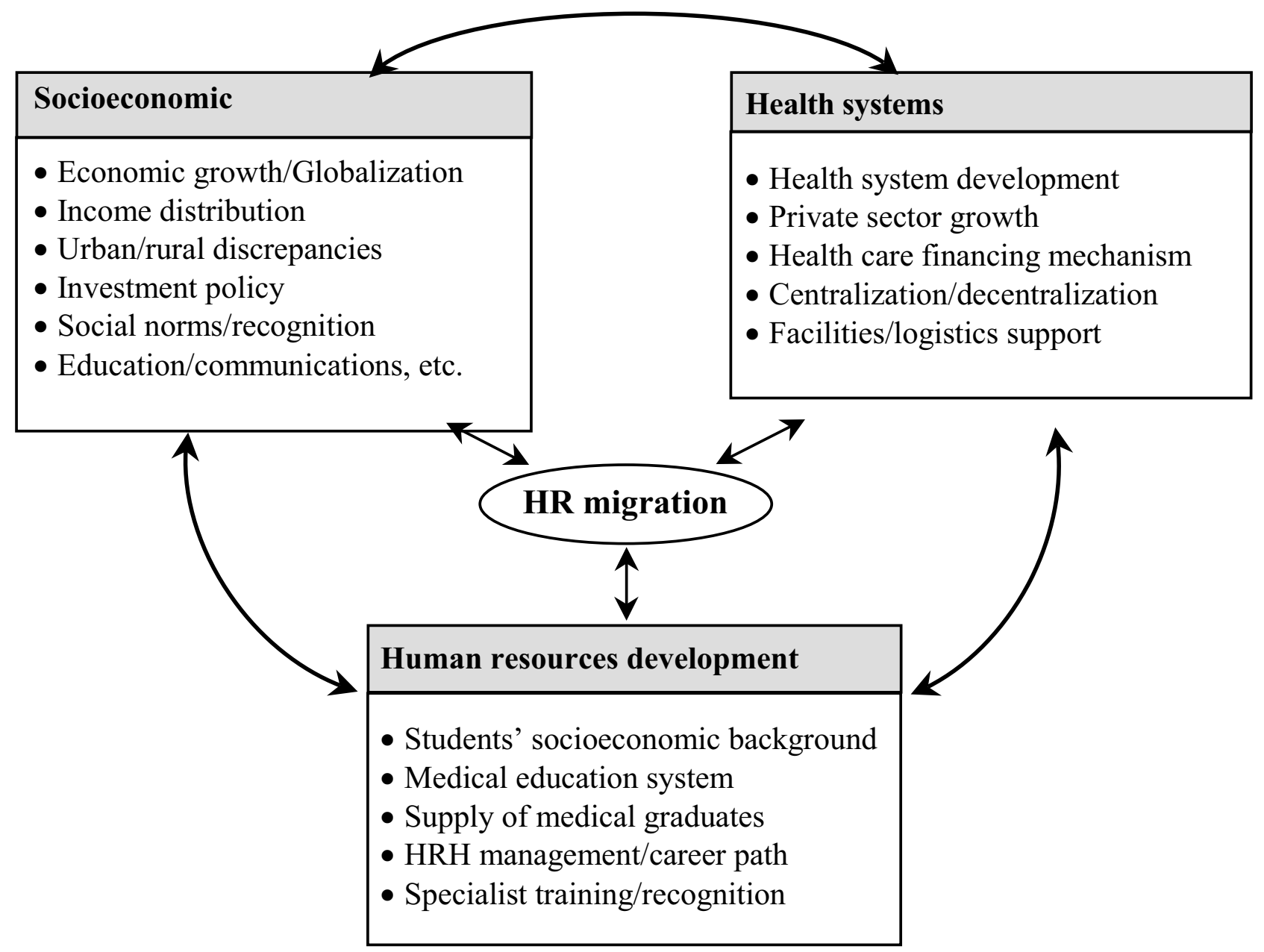

Source: Adapted from Wibulpolprasert S., 1997 [2]

Figure I

Factors determining the distribution of doctors

workforce. The first medical school was established in 1888; later, nursing colleges and schools of dentistry and pharmacy were established. The graduates of these institutions were placed mainly in the country's capital. Because the government at that time realized the difficulties and high cost of expanding health care services by high-level health professionals, lower-level personnel were also produced to deliver essential maternal and child care, immunization and environmental health services in the rural villages. These were mainly midwives and junior sanitarians, who received one or two years of training after junior high school. They worked in a relatively limited number of rural midwifery centres and health centres [4].

It was not until the early 1950s that every province had a provincial hospital, usually quite small (20-30 beds). During that early development period, medical students were offered scholarships with a contract stipulating that they would work for the Ministry of Public Health (MoPH). After graduation, those who did not receive scholarships stayed mainly in the medical schools, and those who received scholarships were sent to the provincial hospitals and some big rural health centres. 


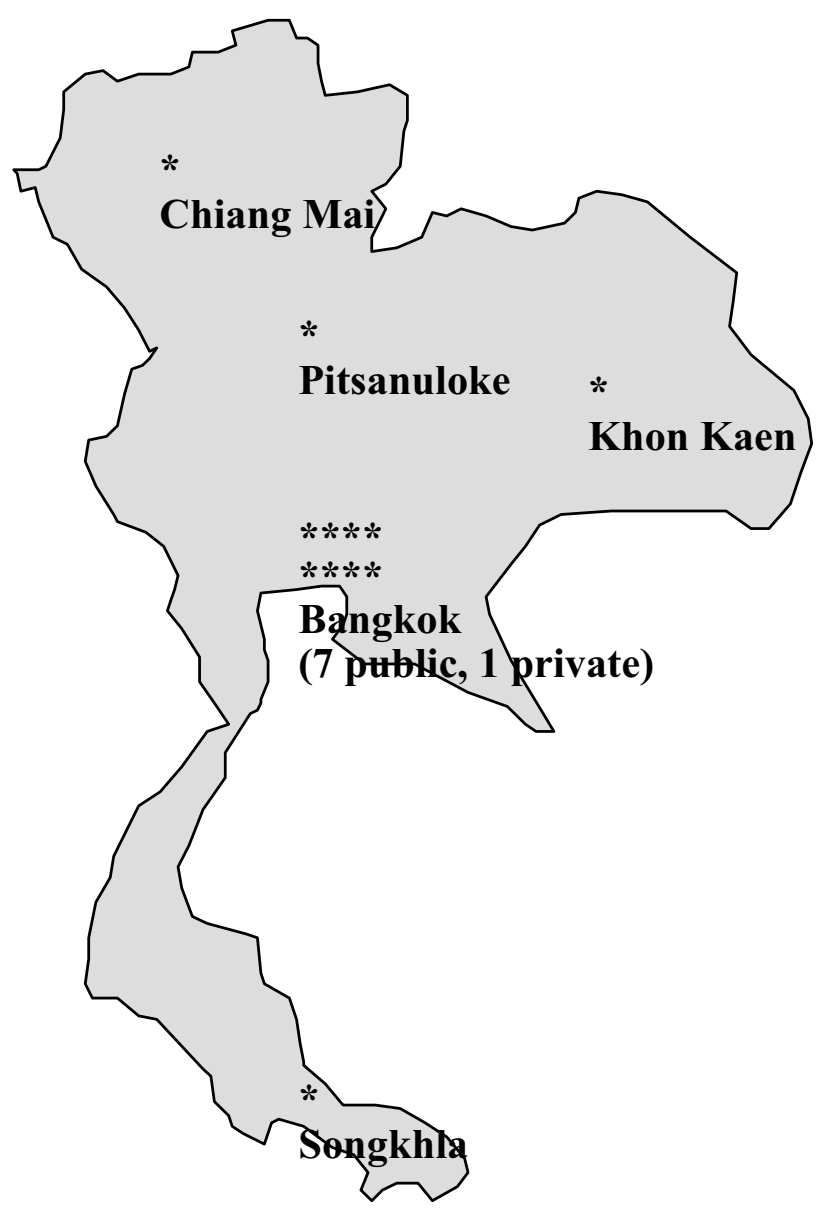

Figure 2

Distribution of medical schools in Thailand

The rural health development policy since 1977 had resulted in a great expansion of rural public health services. There were 728 district hospitals in December 2001, covering more than $95 \%$ of the total rural districts. The district hospitals are 10-bed to 120-bed hospitals; most of them have 30 beds. There were 2725 district hospital doctors, $57.95 \%$ of the total requirement of 4700 . At the provincial level there are 92 hospitals. Twenty-five of them are designated as regional hospitals, with 500 to 1000 beds; the rest are general hospitals, with 150 to 450 beds. There were 5636 doctors in the urban provincial hospitals.

Currently all professionals except graduate nurses are produced mainly by the public universities under the Ministry of University Affairs (MoUA), while paramedics and graduate nurses are produced mainly by the $\mathrm{MoPH}[4,5]$. The recruitment system for the university-trained professionals is quite different from that for the paramedics and most graduate nurses. For the professionals, general national entrance examinations are the main vehicle of recruitment, while the paramedics and most of the graduate nurses are recruited from each province through provincial examination. In 2002 there were 11 public medical schools and one private medical school, producing 1400 graduates (Fig. 2).

After graduation from public medical school each medical graduate has to work for the public for three years. Public doctors can also practise privately, and many of them do. However, if they do not practise privately, they receive USD250 special allowance per month.

\section{History and trends of inequitable distribution of doctors}

For the past four decades, the distribution of doctors to rural Thailand has been divided into four phases:

\section{External brain drain (1960-1975)}

The high demand for doctors in the United States of America during the early 1960s opened tempting opportunities for well-trained Thai doctors to emigrate. It was noted in a 1965 United States Congressional report that the first few batches of graduates from a northern medical school chartered flights to emigrate to the United States. Table 1 shows that in 1965 half of the new medical graduates emigrated, mainly to the United States[6]. During this period, there were fewer than 300 physicians in the very poor rural health system.

The problem of external brain drain of physicians seem to affect most developing countries, especially countries in Africa. In Ghana, it was estimated that during 1985-1997 the cumulative average annual emigration rate was about $14 \%$. This means that $50 \%$ of each batch of medical graduates will emigrate within 4.5 years, mainly to the United Kingdom and the United States [7]. Nevertheless, some countries, such as Cuba, India and the Philippines, produce doctors for export.

This period of external brain drain in Thailand lasted longer than a decade and resulted in the emigration to the United States of approximately 1500 Thai doctors - 25\% of the total at that period - most of them never to return. The result was a severe shortage of doctors in the country, particularly in the rural areas.

\section{Rural development with more equitable distribution}

The rapid exodus of Thai medical graduates prompted the government, in 1968, to enforce compulsory contracts with medical students so that they had to perform three years of public work after graduation or face high fines. The first batch of compulsory-contracted Thai doctors started their assignments in 1972. More importantly, the 
Table I: External brain drain, Thailand

\begin{tabular}{llll}
\hline Year & Total new medical graduates & Emigrants & Percentage of external brain drain \\
\hline 1963 & 233 & 56 & 24 \\
1964 & 236 & 81 & 34 \\
1965 & 276 & 140 & 52 \\
\hline Total & $\mathbf{7 4 5}$ & $\mathbf{2 7 7}$ & $\mathbf{3 7}$ \\
\hline
\end{tabular}

Source: Wibulpolprasert S, 1999 [2]

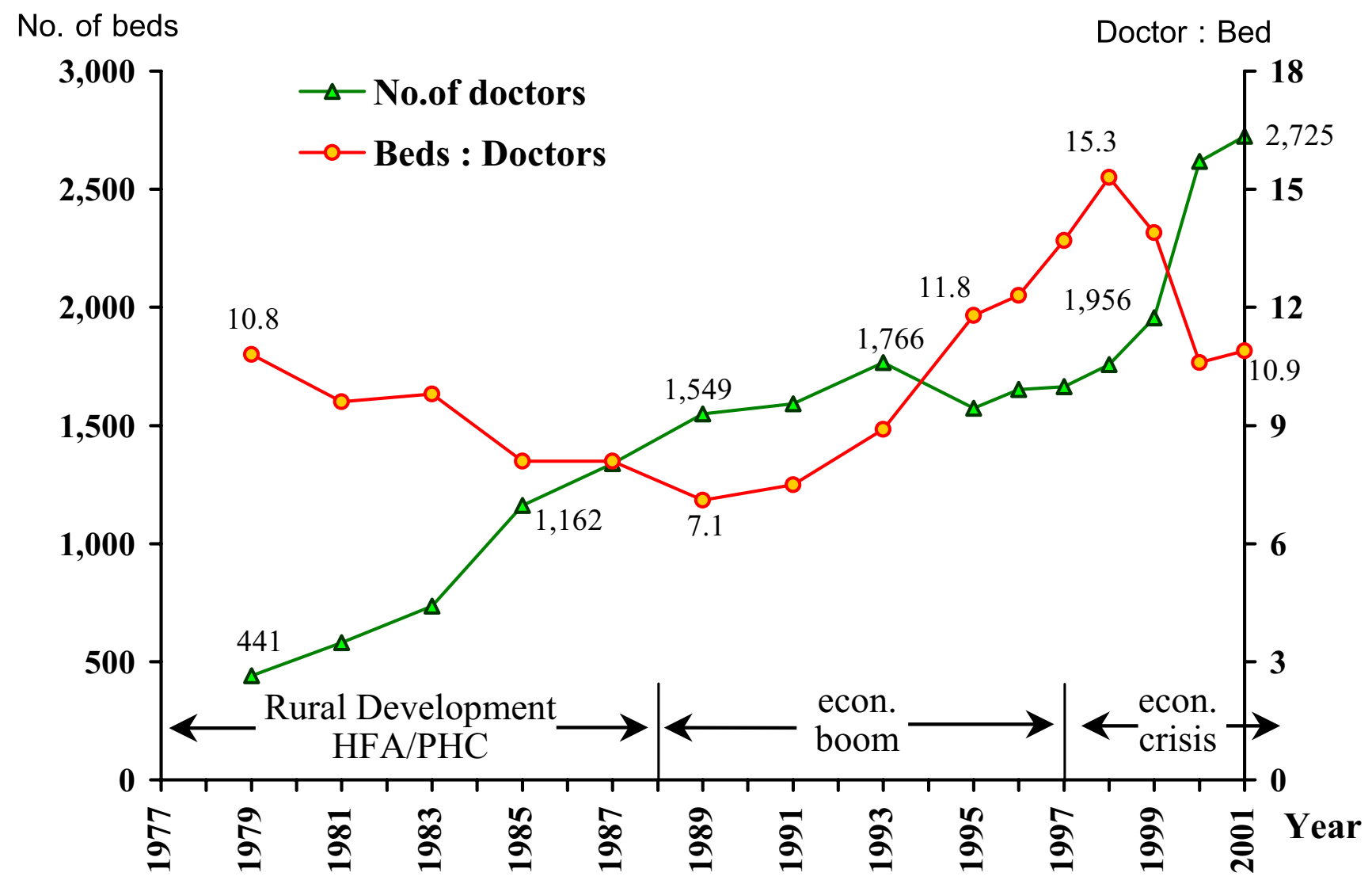

\section{Source: Thailand Health Profile 1999-2000 [3]}

\section{Figure 3}

Numbers of beds and doctors in community hospitals, |977-200I

high level of social awareness during the early 1970s and the democratization movement, followed by the AlmaAta Declaration of Health for All, encouraged a social environment to support the rapid development of rural health infrastructures and a more equitable health sys- tem $[8,9]$. These decisions resulted in an increase in the number of rural hospitals and doctors from 200 and 300 in 1976 to 425 and 1162 in 1985, respectively, a fourfold increase in rural doctors in 10 years (Fig. 3 ). The difference between the doctor:population ratio of the poorest north- 


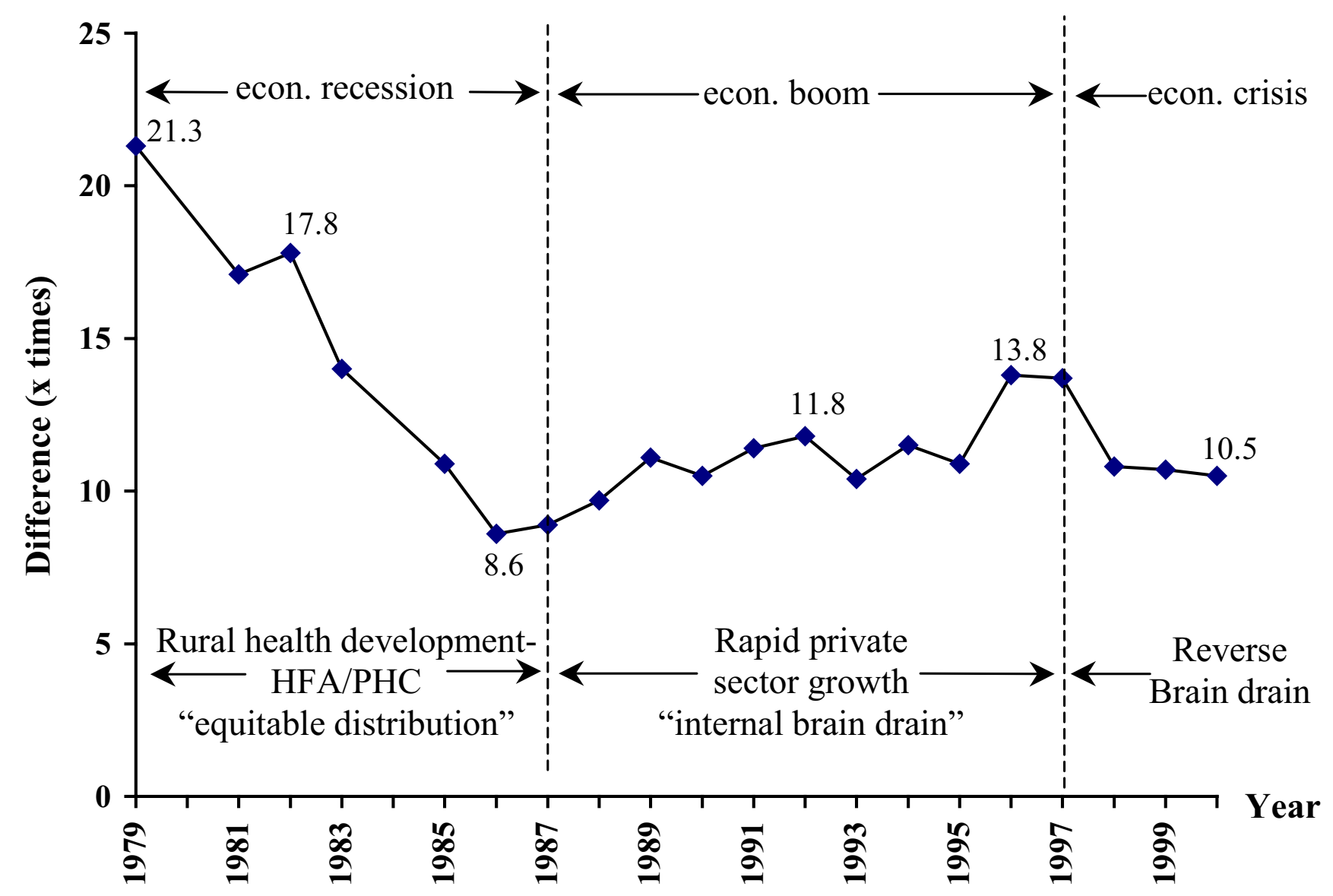

Source: Bureau of Health Policy and Plan, Ministry of Public Health

\section{Figure 4}

Differences between the Northeast and Bangkok population-to-doctor ratios, 1979-2000

eastern region and Bangkok, the capital, dropped from 21 times in 1979 to 8.6 times in 1986 (Fig. 4).

\section{Economic growth and Internal brain drain}

Although the rural emphasis continued, the rapid economic growth and a government investment policy, started in the late 1980s, to support private hospital investment with a free flow of low-interest foreign loans, resulted in a rapid growth of the private health sector in the past decade (1988-1997). This situation created a second period of brain drain, but this time it was internal brain drain from the rural district and provincial hospitals to the rapidly growing urban private hospitals.

In 1986, before the economic boom, the share of private hospital beds and doctors was around 10\%. This figure increased to $25 \%$ in 1995 [3]. Since 1990, while the number of beds in the district hospitals kept increasing, the number of doctors did not increase or sometimes even decreased (Fig. 3). On the other hand, the number of private hospital beds increased, along with the number of doctors. The private hospital doctors increased from 1000 in 1985 to 3300 in 1995, a 3.3-fold increase in 10 years (Fig. 5) [10].

The net loss of doctors (resign-reapply) from the MoPH as compared to new entrants rose from $8 \%$ in 1994 to $30 \%$ in 1997 (Table 2). This situation of internal brain drain was so severe that in April 1997, three months before the economic crisis, 21 district hospitals were without a single full-time doctor [11]. The beds-to-doctor ratio at the district hospitals increased from 7.1:1 in 1989 to $15.3: 1$ in 1998 (Fig. 3) [3]. This increase in workload is also an important factor that pushed the doctors away from the rural district hospitals. The differences of doctor-to-population ratios between the poorest north-eastern region 


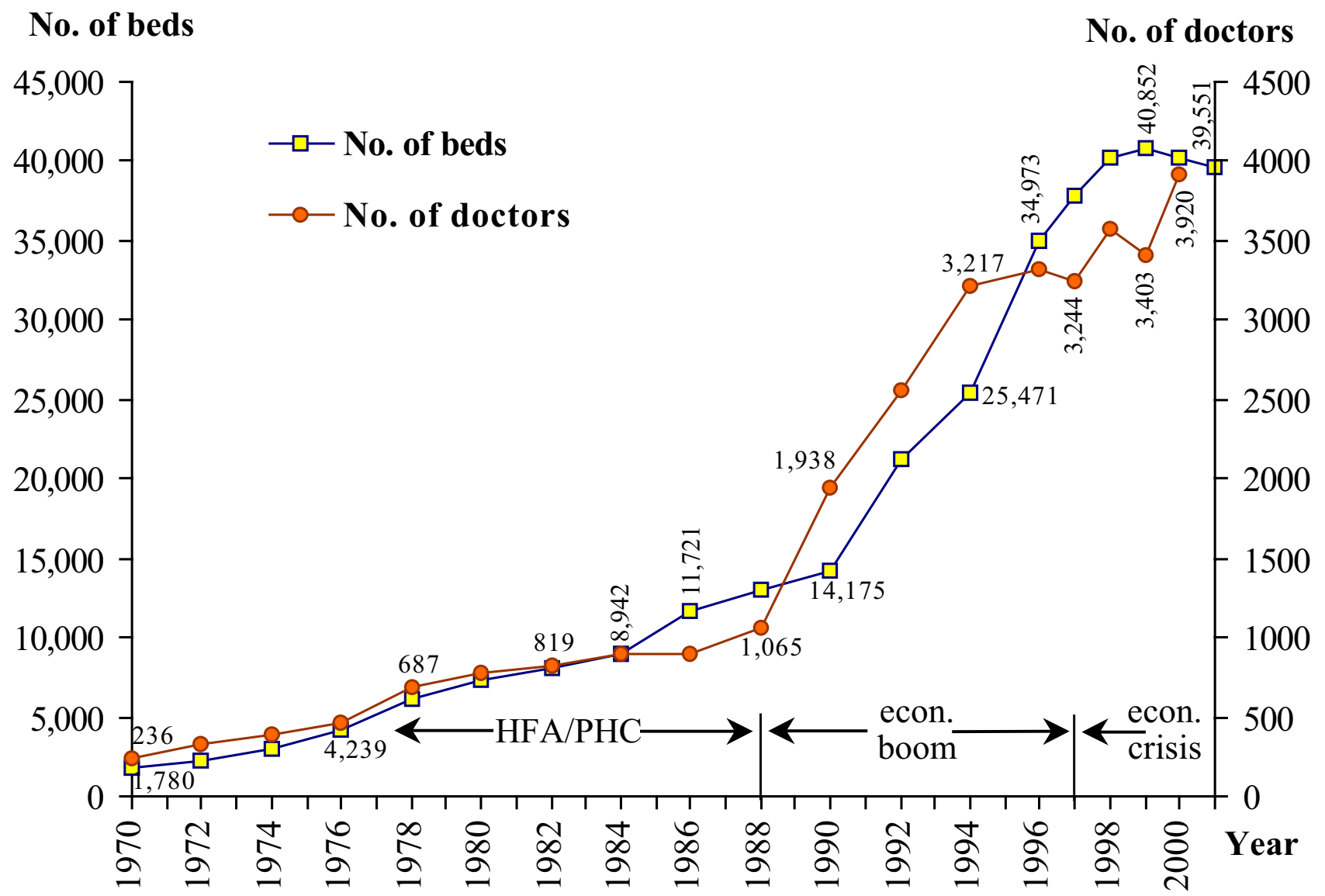

Source: Medical Kegistration Division, Bureau of Health Policy and Plan, MorH

\section{Figure 5}

Private doctors and beds in Thailand, 1977-200I

Table 2: Loss of doctors from the MoPH, 1994-2002

\begin{tabular}{|c|c|c|c|c|c|}
\hline \multirow[t]{2}{*}{ Year } & \multicolumn{4}{|c|}{ Number of doctors } & \multirow[t]{2}{*}{ Percent loss } \\
\hline & Newly graduated & Reapplied & Resigned & Net loss & \\
\hline 1994 & 526 & - & 42 & 42 & 8.0 \\
\hline 1995 & 576 & - & 71 & 71 & 12.3 \\
\hline 1996 & 568 & - & 98 & 98 & 17.3 \\
\hline 1997 & 579 & 30 & 205 & 175 & 30.2 \\
\hline 1998 & 618 & 93 & 117 & 24 & 3.8 \\
\hline 1999 & 830 & 168 & 63 & -105 & -12.6 \\
\hline 2000 & 893 & 92 & 133 & 41 & 4.6 \\
\hline 2001 & 883 & 67 & 135 & 68 & 7.7 \\
\hline 2002 & 913 & 22 & 316 & 294 & 32.2 \\
\hline
\end{tabular}

Source: Personnel Division, Office of the Permanent Secretary, MoPH 
and Bangkok rose from 8.6 times in 1986 to 13.8 times in 1996.

\section{Economic crisis and reverse brain drain}

The severe economic crisis that began in mid-1997 resulted in a rapid decline in demand for private hospital services. Demand for outpatient services in private hospitals declined from 20\% to $70 \%$ [11]. Most private hospitals reduced their numbers of beds and doctors; some of them closed entirely. Rapid reverse brain drain is apparent as the number of district hospital doctors increased from 1653 in 1997 to 2725 in 2001 and the bed-to-doctor ratio dropped from 15.3 in 1998 to 10.6 in 2000 (Fig. 3). The difference between the doctor-to-population ratios of the poorest north-eastern region and Bangkok also dropped, from 13.8 times in 1996 to 10.5 times in 2001 (Fig. 4). The proportion of net loss of doctors also declined greatly, and in 1999 there was a 12\% net gain in addition to new entrants (Table 2). Economic recovery since 2000 and the influx of foreign patients as well as demand for continuing education seems to have started a new round of internal brain drain in 2002 (Table 2).

\section{Strategies used in solving inequitable distribution of doctors in Thailand}

Thailand applied several strategies in response to inequitable distribution of doctors. Further strategies were added as reactions to problems at each phase of development. Some of them are continuous and other were ad hoc.

\section{Development of rural health infrastructure}

To distribute health personnel to the rural areas, the health infrastructure of the rural areas needs to be developed. In 1979 the Thai government initiated rural health development as part of an integrated national rural development project[8]. In order for this policy to be effective in a period of limited resources, the expansion of urban hospitals was completely halted between 1982 and 1986.

The effect was a shift of resources from cities to rural districts, and a rapid increase in the number and capacity of rural district hospitals (Fig. 3) [9]. Good logistic support, housing and other incentives help maintain the necessary workforce. This strategy improved quality and accessibility of services among rural facilities and resulted in a reverse proportion of outpatient visits to the three levels of rural public health facilities, from an inverted triangle to an upright one (Fig. 6).

\section{Educational strategies}

Rural recruitment, training and hometown placement

Rural recruitment, training in rural health facilities, hometown placement after graduation and limited possibilities for private practice are factors that contribute to the suc- cessful distribution of graduate nurses, midwives, junior sanitarians and other paramedics in the Ministry of Public Health[4]. They are now the backbone workforce for the rural health centres and district hospitals. After being recruited through the provincial mechanism, which requires provincial residency, they have to sign contracts with the provincial health office. The contracts require two to four years of public-sector employment in the same province after graduation.

These students are educated in 34 nursing colleges and six public health colleges of the Ministry of Public Health throughout the country. They receive highly subsidized education, including tuition fees at $5 \%$ of actual educational cost and free clothing, dormitory, food and learning materials during their school years. Practical training is carried out mainly in the rural provincial and district hospitals and rural health centres where the students will work after graduation. Thus they are quite familiar with the rural facilities and environment. Most of them, except for nurses and midwives, do not acquire a license to enable them to practise privately.

Attempts to use these strategies for medical education in Thailand yielded some degree of success. The first attempt started in 1974 in one of the central medical schools. Students were recruited from rural provinces by mechanisms that included the participation of provincial health administrators and medical school lecturers. After graduation they were sent back to the provinces/districts from which they came. This system was expanded to other medical schools during the 1980s. Evidence from the experience of one medical school suggested that it lengthened the rural service of the graduates. Two-thirds of the graduates continued their rural placement after the three compulsory contracted years (Table 3) [11].

A study in the north-eastern medical school found that to be more effective, the recruited students need to be restricted to those who were raised in the rural areas. It was found advisable to exclude persons who relocated to rural areas two or three years before enrolment in the hope of being recruited [12]. Due to problems of management of the placement system, the system was terminated in most central medical schools. Only three regional medical schools and one central medical school still allow part of their students to enter under this system. Thus the proportion of rural medical students, which used to be up to $47 \%$ of all medical students in 1983 , went down to $23 \%$ in 1994 (Fig. 7). 


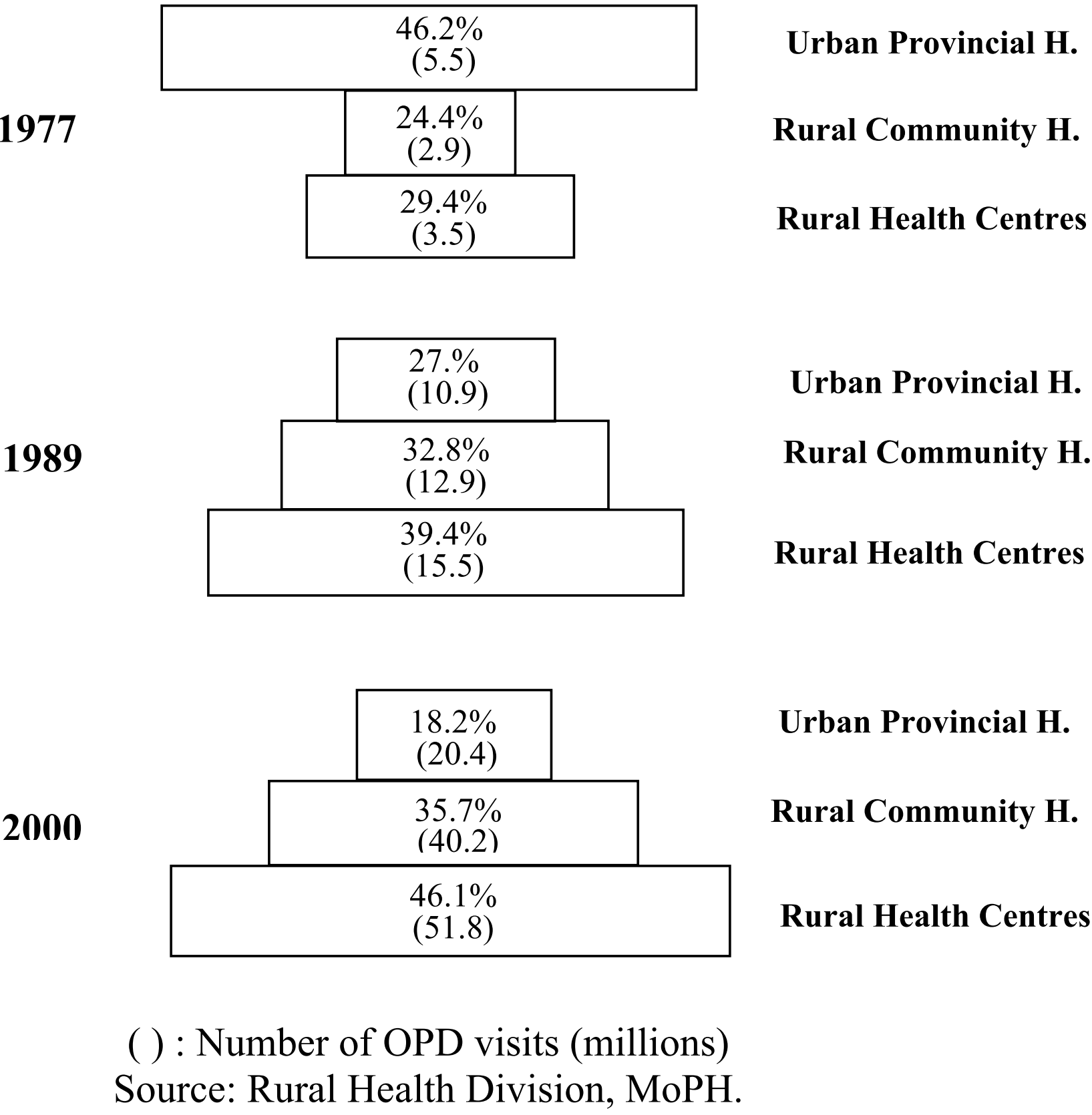

Figure 6

Number and proportion of OPD visits at public health facilities

In 1994 the Ministry of Public Health, in response to the internal brain drain, proposed a 10 -year project (Collaborative Project to Increase Production of Rural Doctors, CPIRD) to produce 300 doctors annually, specifically for the rural areas. The students are recruited by transparent and participatory mechanisms at the provincial level. They spend the first three preclinical years at medical schools (both central and regional) and the second three clinical years at 12 regional hospitals with the networking of district hospitals. This project began by accepting 30 
Table 3: Place of practice of MESRAP graduates

\begin{tabular}{lll}
\hline Batch & \multicolumn{2}{c}{ Percentage in rural districts } \\
\cline { 2 - 3 } & First 3 years & After 3 years \\
\hline $1-9$ & 83.13 & 68.67 \\
10 & 68.57 & 68.57 \\
$11-13$ & 85.34 & - \\
\hline
\end{tabular}

Source: Faculty of Medicine, Chulalongkorn University

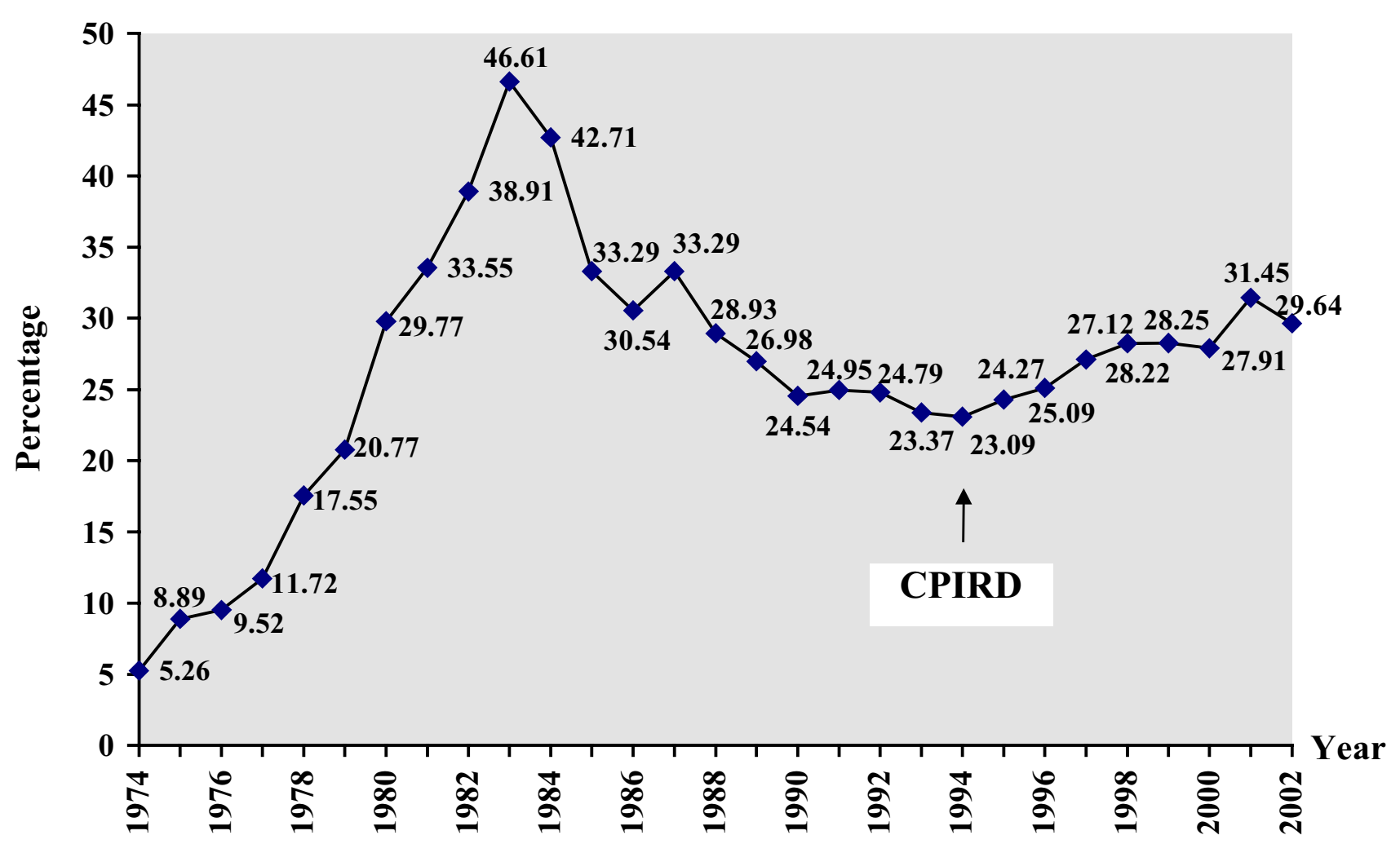

CPIRD $=$ Collaborative Project to Increase Production of Rural Doctors Source: Faculty of Medicine of all universities

\section{Figure 7}

Proportion of rural medical students

students in 1995 and increased to 293 students in 2002[13]. The project also boosted the proportion of rural medical students from $23 \%$ in 1994 to $31.5 \%$ in 2001 (Fig. 7).
In April 1997, at the peak of the economic boom, 113 compulsory-contracted doctors paid fines and resigned from the Ministry of Public Health after one year of compulsory work. Detailed investigation revealed that those with rural backgrounds and who had graduated from regional medical schools had significantly lower 
rates of resignation - less than half of those who originated and graduated from the capital. The three main reasons for the resignations were: to go into private practice, inappropriate relocation and continuing education [14]. It should be noted that rural recruitment and training also proved to be quite effective in achieving rural distribution of doctors in several countries, notably Australia and the United States [15-17].

Establishment of regional medical schools is also a good measure for the equitable distribution of health care services and doctors. Conversely, central medical schools drew doctors into the capital. The resolution of the Fifth National Medical Education Seminar in 1986 stated that "... there should be no new medical schools in the capital and vicinity provinces" [18]. However, since 1986 four new medical schools were established centrally, including one private medical school.

\section{Reform of medical education/specialty training/board qualifications Reform of medical education}

The resolution of the Fourth National Medical Education Conference, in 1979, stated that all medical schools would reform their curriculum to produce medical graduates suitable for working in district hospitals. Four main characteristics of these basic doctors are: good clinical competence, support for primary health care, ability to train paramedical personnel and health volunteers, and good management skills[19]. This resolution resulted in a major reform of medical education, and all medical schools sent their students to be trained at district or provincial hospitals for at least three to six months. Community medicine became one of the major departments in all medical schools. Rural recruitment and training and the hometown placement system also increased.

\section{Specialty training}

To reduce the demand for specialty training abroad, the Thai Medical Council started its specialty training programme in 1971. There are now 42 specialty boards approved by the Thai Medical Council. In 2001 the overall quota for specialty training was 1161 . The real acceptance was 889 trainees, as compared to 1200 new graduates.

Quotas for specialist training programmes have been frozen since 1997. Experience in rural public services is now a prerequisite for the residency training programmes. At least one year of rural services is required for most training, except for some specific specialties such as general practice, pathology, forensic medicine and psychiatry [5]. Rural doctors also fall under a special quota for specialty training, on condition that they return to the district hospitals afterward. However, this control of specialist training received strong resistance from the medical schools.

\section{Board qualification through self-experiential training}

Doctors who have more than five years of work experience in a rural district hospital are eligible to apply for a qualifying board examination. If they pass the examination, they receive a Certificate of Proficiency (called the Thai Board certificate) from the Medical Council of Thailand. This is offered in the specialty of preventive medicine, general practice and family medicine. The Civil Service Commission considers these Thai Board certificates equivalent to a Doctor of Public Health or Doctor of Philosophy degree.

\section{Professional-replacement strategies}

Training in basic medical care capacities for rural health personnel in the health centres was a very important strategy that improved those workers' acceptance by the people and reduced the number of outpatient visits at the hospitals. Nevertheless, although these rural health personnel help screen many patients, there is still a high percentage (35\% to $70 \%$ ) of patients who bypass the health centres in favour of the district and provincial hospitals $[20,21]$.

Training of nurse practitioners to serve in district hospitals where there were inadequate numbers of doctors was started in 1973. It lasted for 13 years and was terminated in 1986 after producing 688 nurse practitioners, due to a reduction in qualified applicants. At present, only $10 \%$ of the graduates still work as nurse practitioners. During the period of rapid increase of rural doctors (1980-1987), the nurse practitioners' role was reduced greatly. Their career opportunities are limited compared to nurses in other services, and they are not allowed to engage in private medical practice. These are the main reasons for the low number of applicants and the rapid loss to attrition [22]. However, some district hospitals still successfully use nurse practitioners or self-trained graduate nurses to provide outpatient services alongside the doctors.

\section{Increased supply}

Many people believe that an increased supply of doctors will eventually lead to better distribution to rural areas. This strategy is very expensive. The operating cost for producing a physician in Thailand was about USD45 000 in 2002. The total cost might go up to USD100000. Evidence from other countries, such as Mexico, showed that an increased supply of doctors alone would not improve distribution, but would instead create an oversupply of doctors $[23,24]$.

In Thailand, increased production of personnel was usually carried out in response to expansion of the public health services and external brain drain. Not until the internal brain drain in the 1990s did increased production begin in response to increased internal demand, in both 


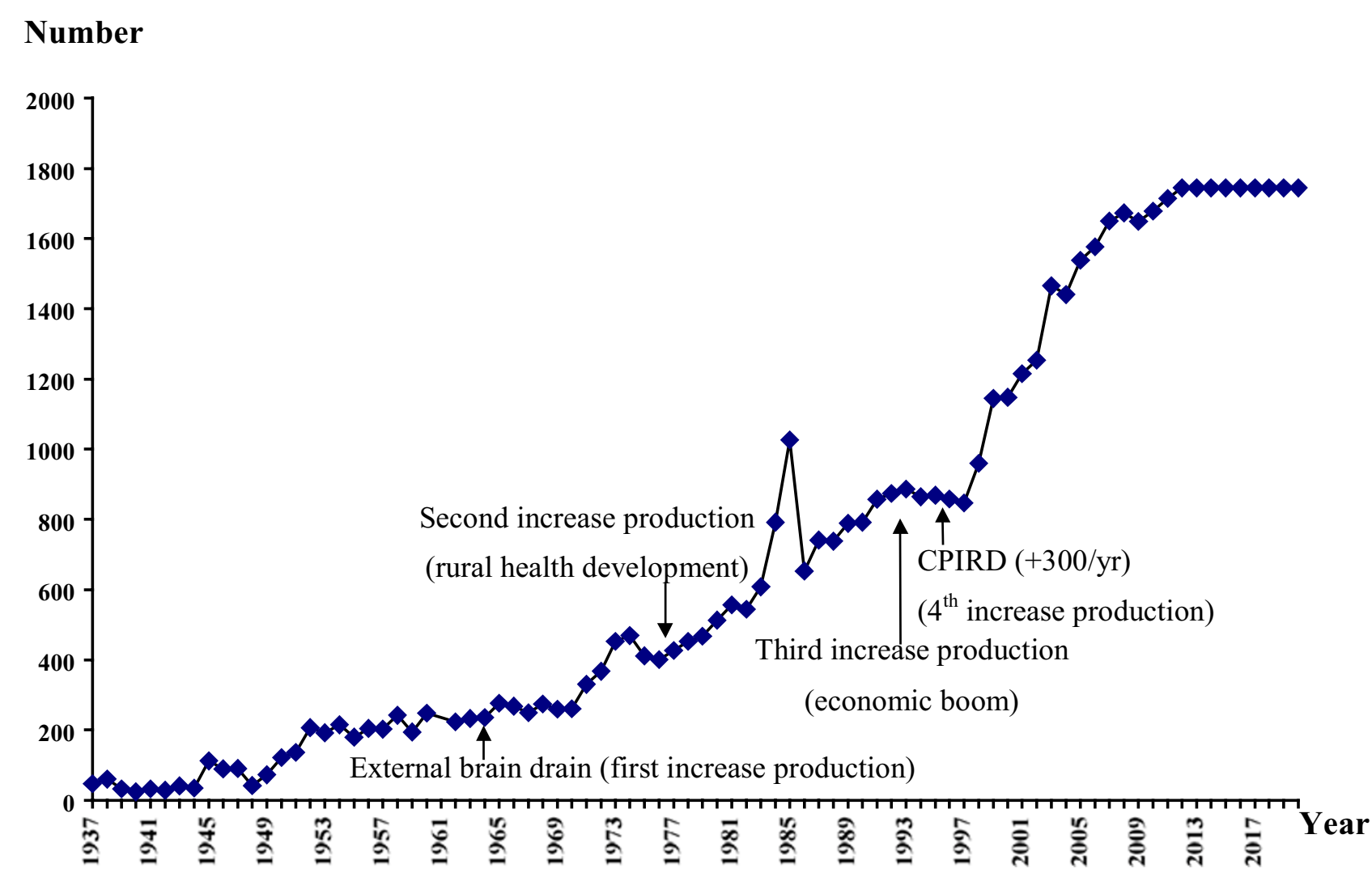

Source: Thai Medical Council

\section{CPIRD $=$ Collaborative Project to Increase Production of Rural Doctors.}

\section{Figure 8}

Annual output of physicians

the public and private sectors. A private, for-profit medical school was established in 1989, with strong opposition from the rural doctor society. Two of their members in the Medical Council Committee resigned and held a press conference to protest against it. Finally the Medical Council ruled that only private medical schools under not-forprofit organizations would be allowed. Since then, no additional private medical schools have been started. Graduates from private medical schools must pass licensing examinations, as compared to the automatic licensing of graduates from public schools.

Figure 8 shows the annual output of physicians. It is evident that the increase in output is a response to external brain drain from demand in rich countries, rural health system development and internal brain drain from increased demand in the private sector. This level of pro- duction may result in a decrease of the population-to-doctor ratio from 3500:1 in 1995 to 1500:1 in 2025, a good balance between requirement and supply $[25,26]$.

Since 1994, due to internal brain drain, many public hospitals have started to hire retired doctors, both GPs and specialists, for part-time services. Rules and regulations for licensing were also modified to facilitate the return of highly skilled expatriate Thai specialists. In 1997, the MoPH also allowed its hospitals to hire as temporary employees foreign graduates who have not passed the licensing examination.

Some richer countries solve these problems by importing foreign graduates to their rural areas. For example, South Africa successfully imported Cuban doctors to its rural health centres[27]. This measure must be used with care, 
as it may cause shortages of doctors in other countries. Some countries, such as India and the Philippines, produce medical graduates for export in order to generate an influx of foreign currency. In 2001 Britain's National Health Service announced a demand of 30000 graduate nurses. Not many Thai nurses are qualified to work in the United Kingdom, due to the language barrier. It has been reported that foreign nurses represented 30\% of the new registrations in the United Kingdom in 1999 [28].

\section{Financial strategies}

Financial strategies were used in five forms:

\section{Voluntary scholarships}

Voluntary scholarships used to be given to medical, dental, pharmacy and nursing students. Those who received the scholarships were obliged to work for two to four years in public service. This system was used in the early days of rural health system development. It did provide some doctors for the early development of MoPH's health service system. This system no longer exists, but some private hospitals give scholarships to graduate nursing students in the faculty of nursing in some universities in exchange for a few years of their work, in order to ensure an adequate number of nursing staff.

\section{Compulsory public service}

This started for physicians in 1967 in response to external brain drain, and the first batch graduated in 1972. In the first four years (1967-1970) it was voluntary: the medical students chose either to work for three years in public facilities or pay a high annual tuition fee (USD400 per year for four years, or USD3000 at 1997 prices). If they breached the contract, they would have to pay a fine of USD4800. This fine was increased to USD8000 and USD16 000 in 1971 and 1973, respectively. Due to high social concern, high tuition fees and little opportunity for private practice, most medical students signed the contract. In 1972 this contract became compulsory for all medical students.

This strategy, combined with rural health service development, high social concern and economic recession with low growth in the private sector, was the main factor contributing to the rapid increase in the number of rural doctors, and the reduced gap of doctor density during the decade between 1980 and 1990 (Figs. 3 and 4). If the fine (USD10 000 in 1998 value - reduced due to devaluation) were adjusted to compensate for inflation, it would now be USD50000 The attempt to increase the fine to correct for inflation was strongly opposed by the medical schools.

\section{Financial incentives}

To provide incentives for doctors who deliver rural services, the government started special hardship allowances for district hospital physicians in 1975 . For regular districts the rate was USD60 per month for the first year, and USD68 per month from the second year of service onward. For more remote areas, the amounts were USD80 and USD88, respectively. These allowances were approximately equal to the monthly salary of the newly graduated doctors. These allowances were increased in 1983 to USD80 and USD88 for regular districts, and USD100 and USD108 for remote districts. It was not until the rapid economic growth with severe internal brain drain that the government initiated increased financial incentives for public doctors.

In 1995, a non-private practice allowance of USD400 per month was given to any doctor (in the MoPH) who agreed not to engage in private practice. To increase productivity, the MoPH in 1995 also started non-official-hours services for elective patients (before that, these services were available only for emergency patients) with special workloadrelated payments [29].

Finally, in October 1997, the government increased the special rural hardship allowances from two levels to three levels. Doctors in regular districts receive USD55 and USD62 per month (reduced because of devaluation). Those in more remote districts receive USD250 per month, and those in the most remote districts (69 districts) receive USD500 per month (almost three times their basic salary).

In total, a new medical graduate working in a rural district may receive from USD825 (in regular districts) to USD1379 per month (in the remotest districts.) But this is still lower than the salary of a new graduate in private practice in an urban area, who has an income of at least USD1500 per month (Table 4) [12].

It should be noted that in Table 4 only one item of the financial incentives was given to compensate for hardship rural practice (item 7 ) and it was hardly related to the length of time of rural work. It has been postulated that these incentives may only make it easier for new graduates to pay the fine for breaking the three-year contract and then move to the big cities.

The three levels of special allowances to rural district doctors also created many inequities. Some district hospitals only $10 \mathrm{~km}$ to $20 \mathrm{~km}$ apart on paved roads experience a 5fold to 10-fold allowance differential. In December 2001, under a new decentralized financial management system of the Universal Health Insurance Policy, these financial incentives became more flexible and decentralized. 
Table 4: Remuneration for MoPH doctors, 2002

\begin{tabular}{|c|c|c|}
\hline Remuneration & $\begin{array}{l}\text { Rate (USD) } \\
\text { (per month) }\end{array}$ & Remarks \\
\hline Salary (new graduate) & 203 & standard salary for PC* 4 level 3 \\
\hline Non-private practice allowance & 250 & anyone without private practice \\
\hline On-call payment (general) & $250-300$ & USD20 per shift (more than 8 hours) \\
\hline $\begin{array}{l}\text { Payment for special procedures during non } \\
\text { official hours }\end{array}$ & $72-126$ & $\begin{array}{l}\text { rate depends on number and kind of procedures; provincial hospital doctors } \\
\text { usually receive much more, sometimes up to USD I,500 }\end{array}$ \\
\hline Special allowance for rare ${ }^{* *}$ specialties & 100 & e.g., Pathologist \\
\hline Professional allowance ${ }^{* *}$ & $90-250$ & for medical profession PC level 7 up \\
\hline $\begin{array}{l}\text { Special allowance for rural district hospital } \\
\text { doctors }\end{array}$ & $50-500$ & $\begin{array}{l}\text { USD } 50-55 \text { for regular districts ( } 532 \text { districts) USD } 250 \text { for remote districts (I } 27 \\
\text { districts) USD500 for the remotest and most difficult districts ( } 69 \text { districts) }\end{array}$ \\
\hline
\end{tabular}

Source: Bureau of Health Policy and Plan, MoPH, 2002 The exchange rate is USDI $=$ THB40 $*$ PC $=$ Position Classification $* *$ Not for new graduates

Increased tuition fees and payback by rural public work There have been proposals to increase the tuition fee to medical students from USD400 to USD7500 per year, to reflect real costs. Those who cannot afford to pay can receive a soft educational loan from the government and either pay back by cash after graduation or pay back by rural work for three years[11]. The United States experience in this system yielded varying degrees of success. It was found that about 30\% pay back the loans by completing three years of rural work, $20 \%$ pay back totally by cash and $50 \%$ pay back both by cash and by working for a shorter period in the rural areas[30]. This proposal may soon be implemented in Thailand when the universities and public hospitals become autonomous in the near future.

Reform of the health care financing system

Under the new Universal Coverage Health Insurance scheme, started in 2001, a new financial management system based on capitation is used[31]. Each Thai citizen who is not covered by a health insurance scheme must register with a hospital. The hospital will be paid a flat rate of USD30 per capita per year. Out of this must come the salaries of all their staff. It is believed that this new financial scheme will create a strong incentive for more equitable redistribution of human resources. After implementation, some big hospitals in the city that formerly were overstaffed refused to take more contracted new graduates. Those in the more populated poor regions, which used to be understaffed, now say they have enough money to hire many more staff.

\section{Social strategies}

A crusading spirit, social recognition and job satisfaction are also very important factors in attracting doctors to rural areas.
The contracted doctors who started to work in rural hospitals in the early 1970s faced many administrative and logistic problems. They were not trained to be managers but had to become hospital directors from their first day after graduation. Many of them unintentionally broke financial and administrative rules of the government. Some of them were cheated by their accountants. Some suffered from failures in personnel management.

In 1978, with pressures mounting, they finally created a society of their own called The Rural Doctor Society. The society started several management training programmes, developed management handbooks and designed innovative activities to support rural district hospital doctors, such as rural doctor journals/newsletters, public recognition for extraordinary performance, visits to rural hospitals by senior doctors for morale support and provincial rural doctor coaches. In 1982 they also established a Rural Doctor Foundation. Their activities boosted their crusading spirit and their pride in belonging to the rural doctor group.

The society became widely accepted in the health arena, among the medical profession and by the public. Members of the rural doctors were able to win several successive elections to the Medical Council Committee. They influenced several changes in medical education and residency training to improve distribution of doctors.

Apart from supporting rural health services, the society also moved actively to support public health movements, such as a national drug policy, an essential drugs list and tobacco control. They also played active roles in the national movement toward democratization and political reform as well as a watchdog role to counteract corruption and inappropriate administrative behaviour. 
In August 1998, they revealed evidence of a nationwide drug purchasing scandal that resulted in the resignation of the health minister and one deputy health minister. One of the advisers to the minister was sentenced to six years' imprisonment. The success of the society boosted the morale of the rural doctors and allowed them to work more happily in the rural district hospitals [32].

Apart from the creation of Rural Doctor Society and Rural Doctor Foundation, several public recognition awards were also established. An annual "hardship award" is given to the best rural doctor in the most remote area. This is in commemoration of one very good rural doctor who was killed during his dedicated services in a border district in 1985. The oldest medical school, Siriraj Hospital, has given a special annual prize for "the best rural doctor of the year" since 1976. The medical association and Medical Council also award the same recognition.

Several medical schools also give special recognition to their alumni who perform outstanding work in the rural districts. Many rural doctors are invited to become parttime and full-time lecturers in medical schools, mainly in the community medicine departments. Some of them also receive honorary degrees from universities. Some of the rural doctors are recognized at the national level as "the model Thai of the year".

\section{Personnel management and logistic support strategies}

Rural doctors, after the three-year compulsory service, are free to relocate to their preferred jobs. Their promotion is also encouraged.

District hospital doctors, as all doctors in the public services, start their career at PC level 4 (of 11 levels). Within seven to eight years of service most of them will be at level 7 , and within 10 to 12 years at level 8 , equivalent to the director of a division in the central MoPH office.

Since October 1996, they can be promoted to the PC level 9 , equivalent to the provincial chief medical officers (their direct bosses) and the deputy director general of a central department in the MoPH. This promotion puts them at a higher level than even the district officer (level 8).

Logistic support with paramedics, drugs and equipment, supplies, housing, transportation and communications has also improved greatly. Most of the rural district hospitals are now very well equipped and supported by adequately trained staff.

\section{Lessons learned and recommendations}

There are many push and pull factors for doctors in the rural areas (Fig. 9). Thailand implemented several strategies to solve inequitable distribution of doctors. Despite these strategies, inequitable distribution of doctors persists.

Doctors usually stay for a short period in the rural district hospitals. Around half of district hospital doctors are those within the first three years of a compulsory contract. This proportion has remained the same for the last two decades (Table 5). In addition, external factors - particularly economic dynamics - strongly affect the distribution.

In the near future, economic recovery and international trade with promotion of the import of foreign patients may boost demand in urban private hospitals, with the return of internal brain drain. Some evidence of this is being observed in 2000-2002 (Table 2).

Several lessons can be drawn from the Thai experience:

- Many strategies have been developed and used to improve inequitable distribution of doctors. They have usually been reactive strategies in response to each crisis. They are fragmented, uncoordinated, sometimes inconsistent and rarely evaluated systematically. Formerly there was a committee, the Coordinating Committee for Medi$\mathrm{cal}$ and Health Issues, to coordinate these strategies. It was very successful in its early days but weakened during the rapid economic growth, and was abolished in 1995 for political reasons.

- The strategies used have improved the distribution of doctors to a certain extent, as evident from the increase in the number and proportion of doctors at the district level. But the fragmented, uncoordinated, inconsistent and sometimes irrational application of strategies resulted in a system that cannot attract doctors to stay in the rural areas when there are strong economic incentives in the urban private sector.

- The combination of rational strategies in packages with unified, integrated, consistent implementation supported by an efficient monitoring system with established national mechanisms is essential for the success of equitable geographical distribution of doctors.

- Finally, more equitable socioeconomic development is the basis for overall sustainable success in social equity. This needs strong political leadership and social support.

The following are recommendations for each strategy for the sustainable equitable distribution of doctors.

\section{Reform of the health care delivery system}

Primary medical care should be the main focus of development in both urban and rural areas. Growth of the sec- 


\section{Pull factors (urban)}

Demand

- in rich countries

- in urban private hospitals

Better living standards

Specialization training

Better income

Higher social recognition

Job satisfaction/career

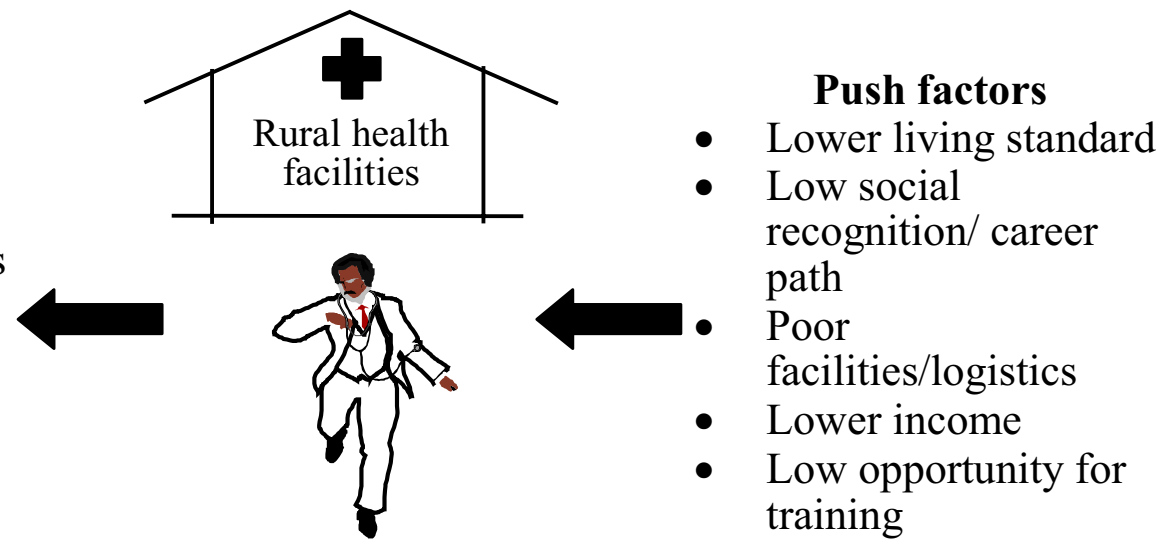

\section{Remedies}

Development of rural infrastructure

- communication

- schools

- facilities/logistics

\section{Education}

- rural recruitment/training/placement

- opportunity for continuous education

- special quotes for training

- $\quad$ support R\&D and qualification

\section{Social}

- $\quad$ special award; career path

- civic movement

Financial

- hardship allowance plus other incentives

- capitation payment systems

- high tuition fees paid by rural works

- compulsory public work

\section{Figure 9}

Push and pull factors and strategies used

ondary and tertiary care hospitals in urban areas in both the public and private sectors should be appropriately planned. No more financial support (tax exemptions, etc.) to open new private hospitals in the cities should be allowed. A system of "certificate of needs" may be established. A good and efficient referral system should be established. This reform can be achieved through financial reform of various insurance schemes. The enactment, in October 2002, of a comprehensive health insurance act focused on strengthening primary care as the gatekeeper, as well as a referral system and financial reform based on capitation payment systems, is expected to greatly improve the distribution of human resources [34].

Health centre personnel should be further trained and supported to deliver good primary care to encourage patients not to bypass local health facilities. Instead of retraining nurse practitioners, which proved not to be very 
Table 5: Contracted and non-contracted rural doctors

\begin{tabular}{lccccc}
\hline Year & Total rural doctors & \multicolumn{2}{c}{ Non-contracted } & \multicolumn{2}{c}{ Contracted } \\
\cline { 3 - 6 } & & Number & $\%$ & Number & $\%$ \\
\hline 1982 & 628 & 175 & 27.87 & 453 & 72.13 \\
1984 & 934 & 377 & 40.36 & 552 & 731 \\
1987 & 1,339 & 602 & 44.96 & 1,415 & 59.10 \\
2001 & 2,389 & 974 & 40.77 & 1,473 & 59.23 \\
2002 & 2,651 & 1,178 & 44.44 & 5.56 \\
\hline
\end{tabular}

Source: 1982-1987 from Jindawatthana A [2I] 200I-2002 from Health Service Network Development Office, MoPH

successful, on-the-job training in basic medical care provided to the existing district hospital graduate nurses would be more effective and sustainable.

\section{Reform of medical education}

Rural recruitment and training in rural district and provincial hospitals should be continuously promoted. Only those who originate from the rural areas should be eligible to enter this system. A system of support to junior high school students in each rural district, probably by the district hospitals and the schools, should be developed to prepare candidates for this system. This would allow a higher proportion of students recruited from poorer families in the rural districts. These students should be trained in the existing rural health infrastructure, including the district hospitals, particularly during their clinical years.

If there is an increase in demand in the future, the increased production should not be based on creating new and centrally placed medical schools, but should depend on a flexible collaboration project between the $\mathrm{MoPH}$ and the existing medical schools. Rural district hospitals can be very good training institutions for basic medical doctors with little additional investment. Rural recruitment and rural training must be the compulsory systems for any future additional production.

The current quota for specialist training of 1161 should be tightly controlled to prevent loss of rural doctors into training programmes as well as to reduce overspecialization.

\section{Financial strategies}

Financial incentives should be more flexible yet focused. A decentralized financial management system is preferable. There could be many more rates of hardship allowance, as compared to the three fixed rates determined by the central ministry. The rates should also better reflect how long the doctors work in the district.
The fine for early termination of compulsory public services must be adjusted to reflect inflation. Replacement of a compulsory public contract with cost-related tuition fees and payback by rural work should be applied gradually and cautiously and in conjunction with other strategies.

\section{Personnel management}

The guidelines for promotion of district doctors (in this case to PC level 9) should be implemented extensively. This would benefit those who work for more than 10 years in the district. Relocation after the three-year compulsory period should be fairly free, particularly to the other rural district hospitals in any province.

\section{Social strategies}

Social movement towards acceptance and appreciation of rural district hospitals and health centre personnel should be continued and further strengthened. The Rural Doctors Society and Foundation should receive more social support and understanding from the MoPH to allow them to pursue positive activities to improve motivation of young graduates.

\section{Institutional support for HR policy/management}

A national mechanism to coordinate health systems and human resources development at the high policy-making level is essential for the consistency and sustainability of development strategies. In Thailand, this mechanism is proposed in the new National Health Bill, which is expected to be enacted in 2003 [35].

\section{Competing interests}

None declared.

\section{References}

I. Wibulpolprasert S: Human Resources for Health Development in the Context of Health Sector Reform. A training module for the Flagship training courses in Health Sector Reform. Washington DC: World Bank 1997.

2. Wibulpolprasert S: Inequitable distribution of doctors: Can it be solved? Human Resources for Health Development Journal 1999, I:2-39.

3. Wibulpolprasert S, Ed: Thailand health profile 1999-2000. Bangkok: Veteran Press 2002. 
4. Jindawatthana $A$, MilintangKul $U$, Rajataramya B: Future policy options for HRH production in the Ministry of Public Health, Thailand. Human Resources for Health Development Journal 1998, 3:43-54.

5. Milintangkul $\mathrm{U}$ : Equivalence determination of qualifications and degrees for education and training of health professions in Thailand. Human Resources for Health Development Journal 1997, 2:135-147.

6. Sawetajinda C: Measures for bonding of medical graduates for public services. Bangkok: Civil Service Commission 1997. mimeograph in Thai

7. Dovlo D, Nyonator F: Migration by graduates of the University of Ghana Medical School: a preliminary rapid appraisal. Human Resources for Health Development Journal 1999, 1:42-54.

8. National Economic and Social Development Board: The fifth national economic and social development plan, 1982-1987. Bangkok: Veteran Press 1982. in Thai

9. Wibulpolprasert S: Distribution of health resources in Thailand. In Proceedings of the First Thai Health Assembly Bangkok: National Health Foundation; 1989. in Thai

10. Wibulpolprasert $S$, Suksiriserikul $S$, Chunharas $S$ et al.: Equity in health and health care in Thailand. Bangkok: Health Systems Research Institute 1997. A paper presented at the Travelling Seminar on Equity in Health, organized by the Kaiser Family Foundation, Nasugbu, Philippines, 29 June-6 July 1997, mimeograph

II. Wibulpolprasert S: Economic uncertainties: future challenges to world health. Lessons learned from Thailand. In Health by the people: a cerebration of the life of Ken Newell Liverpool: Liverpool School of Tropical Medicine; 200I.

12. Watanasup W, Thansuhutra K, Sunphitak $N$ et al.: Implication of medical student recruitment on distribution of doctors. Thai Medical Council Bulletin 1993, I I:573-577. in Thai

13. Praboromrajchanok Institute for Health Manpower Development, Ministry of Public Health: Project to increase production of doctors for the rural areas (1995-2005). Bangkok: Proboromrajchanok Institute 1995. mimeograph in Thai

14. Wongwacharapaiboon P, Wibulpolprasert S, Sirikanokwilai N: Factors related to resignation of newly medical graduates from the MoPH in 1997. Human Resources for Health Development Journal 1999, I:30-41.

15. Rabinowitz HK: Recruitment, retention, and follow up of graduates of a program to increase the number of family physicians in rural and underserved areas. N Eng J Med 1993, 13:934-9.

16. Rabinowitz HK: Evaluation of a selective medical school admissions policy to increase the number of family physicians in rural and underserved areas. N Eng J Med 1998, 8:480-6.

17. Rolfe IE, Pearson SA, O'Connell DL et al.: Finding solutions to the rural doctor shortage : the rules of selective versus undergraduates medical education at Newcastle. Aust NZ J Med 1995, 5:512-7.

18. Mahidol University: Report of the Fifth National Medical Education Seminar, 8-12 September, 1986, Bhumiphol Adulyadej Hospital. Bangkok: Mahidol University Press 1987. in Thai

19. The Organizing Committee, Thai Medical Council: Report of the Fourth Medical Education Seminar, Ambassador Hotel, 3-5 October 1979, Bangkok. Bangkok: Thai Medical Council 1980. mimeograph in Thai

20. Wirojseangaroon S: Five year report of the Ayuthaya health system development project. Ayuthaya: Provincial Health Office 1995. mimeograph in Thai

21. Jindawatthana $A$, Wibulpolprasert $S$ : Family doctor practice at district hospital: Case studies of $\mathbf{4}$ district hospitals. Bangkok: Praboromrajchanok Institute for HRD 1998. mimeograph in Thai

22. Wibulpolprasert S, Sirikanokwilai N: Requirement for Thai doctors in the next two decades, in Research for Health Manpower Development. Bangkok: Health Systems Research Institute 1997. mimeograph in Thai

23. Bankowski Z, Fullop T: Health manpower out of balance: conflicts and prospects. Highlights of The Acapulco Conference, 7-12 September, 1986. Geneva: World Health Organization 1987.

24. Frenk J, Alagon I, Nigenda G et al.: Patterns of medical employment: A survey of imbalance in urban Mexico. American Journal of Public Health 1991, 81:23-19.

25. Suwanakij T, Sirikanokwilai N, Wibulpolprasert S: Supply projection for physicians in Thailand in the next 25 years (1996-
2020 AD). Human Resources for Health Development Journal 1998 , 2:117-128.

26. Sirikanokwilai N, Wibulpolprasert S: Modified population-to-physician ratio method to project future physician requirement in Thailand. Human Resources for Health Development Journal 1998, 3:55-67.

27. Health Systems Trust and the Henry J. Kaiser Family Foundation: South African Health Review Durban: Fishwick Printers; 1996.

28. Martineau T, Buchan J: $\mathbf{H R}$ and the success of health sector reform. Human Resources for Health Development Journal 2000, 3:174-183.

29. Pannarunothai S, Srithanrongsawat S: The benchmarks of fairness for health system reform: the tool for national and provincial health development in Thailand. Human Resources for Health Development Journal 2000, I:I3-26.

30. Hsiao W: KT Li Professor of Economics, Harvard University School of Public Health 1997. Personal communication

3I. Health Care Reform Project, Ministry of Public Health: Guidelines for implementing universal coverage for the transition period. Bangkok: Printing Press, Express Transportation Organization 200I. in Thai

32. Wibulpolprasert S, Prakongsai P, Kanchanachitra C: Rural doctor movement: a case study of civic movement in health. Bangkok: Usa publishing 2003. in Thai

33. Wibulpolprasert S, Hempisut P, Pitayarangsarit S: Implication of General Agreement on Trade in Services on human resources for health. Bangkok: Usa publishing 2002. in Thai

34. Royal Gazette: The National Health Insurance Act Bangkok; 2002.

35. Health Systems Reform Office: The draft of the National Health Bill, 2002. Bangkok: Health Systems Reform Office 2002.
Publish with Bio Med Central and every scientist can read your work free of charge

"BioMed Central will be the most significant development for disseminating the results of biomedical research in our lifetime. "

Sir Paul Nurse, Cancer Research UK

Your research papers will be:

- available free of charge to the entire biomedical community

- peer reviewed and published immediately upon acceptance

- cited in PubMed and archived on PubMed Central

- yours - you keep the copyright

Submit your manuscript here:

http://www.biomedcentral.com/info/publishing_adv.asp
BioMedcentral 